\title{
Aa. Vv., Fortunes de Musset
}

\section{Esther Pinon}

\section{OpenEdition}

\section{Journals}

\section{Édition électronique}

URL : http://journals.openedition.org/studifrancesi/3802

DOI : 10.4000/studifrancesi.3802

ISSN : 2427-5856

\section{Éditeur}

Rosenberg \& Sellier

\section{Édition imprimée}

Date de publication : 1 décembre 2012

Pagination : 593

ISSN : 0039-2944

\section{Référence électronique}

Esther Pinon, «Aa. Vv., Fortunes de Musset », Studi Francesi [En ligne], 168 (LVI | III) | 2012, mis en ligne le 30 novembre 2015, consulté le 06 mars 2021. URL : http://journals.openedition.org/studifrancesi/ 3802 ; DOI : https://doi.org/10.4000/studifrancesi.3802

Ce document a été généré automatiquement le 6 mars 2021.

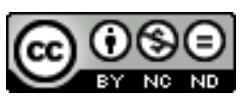

Studi Francesi è distribuita con Licenza Creative Commons Attribuzione - Non commerciale - Non opere derivate 4.0 Internazionale. 


\section{Aa. Vv., Fortunes de Musset}

\section{Esther Pinon}

\section{RÉFÉRENCE}

AA. VV., Fortunes de Musset, Paris, Classiques Garnier, «Rencontres», 2011, pp. 413.

1 Simon Jeune, dans Musset et sa fortune littéraire (Saint-Médard-en-Jalles, Guy Ducros, 1970), puis Loïc Chotard, André Guyaux, Pierre Jourde et Paolo Tortonese dans le volume de la collection «Mémoire de la critique» consacré à Musset (Alfred de Musset, textes réunis par Loïc Chotard, André Guyaux, Pierre Jourde et Paolo Tortonese, Presses de l'Université de Paris-Sorbonne, «Mémoire de la critique», 1995), avaient déjà posé les bases d'une étude de la réception des œuvres de celui que la fin du xix ${ }^{e}$ siècle et le début $\mathrm{du} \mathrm{xx}^{\mathrm{e}}$ nommaient volontiers «le Poète». Néanmoins le sujet, particulièrement vaste tant l'auteur a suscité de réactions contrastées, appelait d'autres développements qu'offre enfin, à l'occasion du bicentenaire de Musset, le volume dirigé par André GUYAUX et Frank LESTRINGANT.

L'un des intérêts majeurs de l'ouvrage réside dans la diversité des domaines abordés: si l'approche littéraire demeure centrale, elle s'enrichit également de perspectives historiques et politiques, et d'une ouverture à tous les supports, arts ou médias, dans lesquels s'exprime une pensée du littéraire. Ce principe de diversité se manifeste dès l'article inaugural de Frank LESTRINGANT (Musset, du Second Empire à la Troisième République, pp.7-23) qui, plus qu'une introduction, constitue déjà un panorama approfondi et recontextualisé de l'accueil réservé à Musset depuis les dernières années de sa carrière et pendant le siècle qui suit sa disparition.

3 C'est également à cette période que s'intéresse la première partie de l'ouvrage, dont les articles sont consacrés à l'impact de Musset sur ses contemporains Gautier (Aurélia CERVONI, Gautier lecteur de Musset, pp. 27-36), Sand (Françoise SYLvos, "André del Sarto", "Les Maîtres mosaïstes" et "Le Fils du Titien". Parallèles et contrepoints, pp. 37-53) et SainteBeuve (Michel BRIX, De l'«enfant du siècle» au mal du siècle. Musset vu par Sainte-Beuve, pp.55-72), puis au rejet mêlé d'attraction qu'il provoque chez les générations qui 
suivent: Gianni Іотті montre la complexité de l'attitude de Flaubert à l'égard de l'auteur de Rolla (Flaubert et Musset, pp. 73-84); Yann MoRTeletTe dresse un bilan nuancé de sa réception par les Parnassiens (Musset au ban du Parnasse, pp. 85-101); André GuYAux le rapproche de Huysmans et Baudelaire via Gamiani et les illustrations de Félicien Rops (Huysmans, Baudelaire et Rops, lecteurs de "Gaminani", pp. 103-114); et Patrizio TUcCI analyse la place qui lui revient dans l'œuvre d'Aragon («Nous vivons d'analogies». Musset (et $M^{\text {Ile }}$ Rachel) dans "Blanche ou l'oubli" d'Aragon, pp. 125-144). À ces études intertextuelles s'ajoute celle de Vital RAMBAUD, qui relate et éclaire les célébrations du centenaire de la naissance de Musset (Le centenaire de 1910, pp. 115-123). La section suivante retrace les liens féconds que l'œuvre de Musset entretient avec la peinture, le dessin et la sculpture. Stéphane GUÉGAN met en question l'oubli relatif dans lequel sont tombés les textes de Musset critique d'art (Infortunes du "Salon de 1836", pp.147-157), Hélène VÉDRINE revient sur la réception de l'auteur au XIX ${ }^{e}$ siècle, mais sous l'angle des éditions illustrées de ses œuvres (Musset dans le livre illustré au XIXe siècle, pp. 159-199), tandis que Frank LESTRINGANT s'intéresse, à travers le Rolla de Gervex, à un autre mode de relecture picturale de Musset (La dernière incarnation de "Rolla". De Musset à Gervex, pp. 201-229). Enfin, Laure PINEAU envisage les fortunes de Musset au tournant des $\mathrm{XIX}^{\mathrm{e}}$ et $\mathrm{XX}^{\mathrm{e}}$ siècles à travers l'histoire mouvementée des statues qui lui ont été consacrées (Les statues à la mémoire de Musset, pp. 231-256). Les articles de Jacques DUPONT, Didier ALEXANDRE et Patrick BERTHIER (respectivement: Musset dans les histoires littéraires, pp. 259-278, Musset dans les anthologies de poésie française, pp. 279-296, et Musset dans les manuels scolaires, pp. 297-310) composent la troisième partie et constituent un intéressant exercice de médiologie, car ils révèlent à quel point l'image d'un auteur est conditionnée par les supports qui la véhiculent. Une dernière partie propose enfin de suivre les réinterprétations de Musset sur les planches et à l'écran: Hervé LACOMBE (Musset en musique, pp. 313-325) et Hélène LAPLACE-CLAVERIE ( Y a-t-il une fortune chorégraphique de Musset?, pp. 341-355) analysent les usages que les musiciens et les chorégraphes ont pu faire des textes de Musset, et Sylvain LEDDA interroge la place des mises en scène de Fantasio, pièce perçue comme métalittéraire, dans la réception de l'œuvre de Musset (Fortunes de "Fantasio", pp. 327-339). Quant aux articles d'Olivier CURCHOD (Aux sources de "La Règle du jeu": "Les Caprices de Marianne" de Musset à Renoir, pp. 357-371) et Valentina PonZETTO ("Comédies et proverbes", de Musset à Rohmer, pp. 373-396), ils révèlent la postérité cinématographique féconde de la dramaturgie mussétienne.

4 Au terme de ce parcours, le lecteur des Fortunes de Musset dispose de clefs nouvelles pour aborder un auteur aux visages multiples, tour à tour adoré et haï, et voit l'œuvre de Musset et les époques qu'elle a traversées s'éclairer mutuellement. La variété des angles d'étude s'avère en effet particulièrement pertinente pour saisir sans la réduire la diversité constitutive de l'œuvre mussétienne, mais, en même temps qu'une image nuancée d'une œuvre dont on voit se ramifier les prolongements, c'est une approche originale de deux siècles d'histoire culturelle qui nous est ici offerte. 